\section{The role of anterior ganglia in phototaxis and thigmotaxis in the earthworm*}

\author{
JOHN H. DOOLITTLE \\ Sacramento State College, Sacramento, Calif. 95819
}

The role of the supra- and subpharyngeal (anterior) ganglia in thigmotaxic and phototaxic behavior in the earthworm (Lumbricus terrestris) was studied. In the first experiment, thigmotaxis reduced negative phototaxis for both worms whose anterior ganglia were removed and control worms. Therefore, the thigmotaxic effect appeared independent of the anterior ganglia. In the second experiment, the role of the anterior ganglia in the accuracy of escape from a directional light was studied. Earthworms with intact anterior ganglia did not escape the light significantly more accurately than earthworms without anterior ganglia.

Bullock \& Horridge (1965) have recommended additional study of the neural basis of behavior in the earthworm because of the relative accessibility and simplicity of its nervous system as compared with higher forms. Indeed, a number of researchers have begun intense investigation of earthworm behavior and its neural basis. Unfortunately, these investigations have concentrated on learning, a variable of relatively little significance to nonlaboratory earthworms. The present study was part of a series concentrating on the neural basis of motivation in the earthworm.

Perhaps the simplest forms of motivated behavior in earthworms are kineses and taxes. Kineses are undirected reactions to stimuli, while taxes are directed toward (positive) or away from (negative) the source of stimulation. Some evidence already exists on taxic behavior in the earthworm, particularly for negative phototaxis, where earthworms move away from bright light, and positive thigmotaxis, where earthworms maximize physical contact with the environment (Smith, 1902).

Further experiments have dealt with the interaction of taxes. Smith (1902) has indicated that earthworms were more negatively phototaxic when bodily contact with the substrate (positive thigmotaxis) was minimized. This finding was supported by experiments by Ratner \& Gardner (1968) and Doolittle (1971). Smith found, however, that removal of the supra- and subpharyngeal (anterior) ganglia of earthworms greatly reduced this influence of thigmotaxis on negative phototaxis. An experiment by Ratner \& Gardner (1968) on earthworms with the anterior ganglia removed showed that, although thigmotaxis had no effect on

* A preliminary form of this paper was read at the Annual Meeting of the Western Psychological Association. San Francisco, April 1971. backward responses to light, it did reduce forward responses. Experiment 1 attempted to resolve this apparent discrepancy by testing earthworms deprived of their anterior ganglia on a task developed by Doolittle (1971) to asseas the effects of thignotaxis on negative phototaxis by measuring escape latencies.

\section{EXPERMMENT 1}

A factorial design, with two operations (removal and nonremoval of the anterior five segments), two phototaxic conditions (light and no light), and two thigmotaxic conditions (alley and no alley), was used. The Ss, 40 adult earthworms (Lumbricus terrestris), were ascigned randomly to one of the eight experimental conditions until each condition had five Ss. Prior to selection, the worms were maintained in $1 \times 2 \times 1 \mathrm{ft}$. wooden box containing moist sandy loam, to which leaves and cornmeal were added for food. After selection, Ss were kept individually in 1-pint plastic cartons, with lids, to which a small amount of aged tap water was added to prevent desiccation. The apparatus consisted of a wooden surface marked with a 3-in.-diam circle and an 11-in-diam circle sharing the same centers. The surface was covered with damp paper toweling, through which the underlying circles were visible. The bulb of a high-intensity lamp (Penetray No. 93) was located $61 / 2$ in. above the center of the circles. Two $1 / 2 \times 1 / 2 \times 12$ in. pieces of wood were placed $3 / 32$ in. from a diameter of the circle in such a way as to form a removable alley, $3 / 16$ × $1 / 2 \times 12$ in., over the center of the circles. The room was illuminated by a 25-W ruby-red bulb.

For Ss assigned to an operations group calling for the removal of the anterior five segments, surgery foliowed the procedure outlined by Ratner \& Stein (1965). For removal group Ss, an 8-h rest period followed to allow for recovery from the surgery. During this period, Ss assigned to groups not calling for the removal of the anterior five segments were also left untreated. No attempt was made to perform sham operations on the nonremoval group Ss.

For Ss assigned to an alley group, the pieces of wood were placed to form an alley; for Ss assigned to a no-alley group, the pieces of wood were removed. For the no-alley groups, each $\mathbf{S}$ was given one trial. This consisted of placing the $S$ within the 3 -in. circle and recording the time taken for the $S$ to extend its first segment (prostomium) over the 11-in. circle. For the alley groups, the procedure was the same, except that the $\mathbf{S}$ was placed in that portion of the alley marked off by the 3 -in. circle to initiate the trial. An arbitrary upper limit of $15 \mathrm{~min}$ was set, at which time the trial was terminated if the $S$ had not responded. For Ss assigned to light groups, the high-intensity light was on throughout the trial. This incandescent light raices the surface temperature $1^{\circ} \mathrm{F}$ in $15 \mathrm{~min}$, indicating only slight heat and light confounding. The Ss were run in blocks such that one $S$ in each group was run before a second $S$ in any group. Within blocks, the order of running was random. No record was kept of the presence and amount of mucous secretions in the test area.

Results

The mean response times for the eight groups is presented in Table 1. The following Mann-Whitney $U$ comparisons were made: (1) To assess the effects of the operations, the response times of $S s$ in the removal and the nonremoval of the anterior fire segments conditions were compared ( $U=185, p>.05) ;(2)$ to anses the effects of the alley, the response times of $S s$ in the alley and no-alley conditions were compared ( $U$ $=60, p<.001$ ): (3) to ascess the effects of the light, the response times of Ss in the light and no-light

Table 1 Mean Revponse Tires in Second

\begin{tabular}{|c|c|c|c|c|}
\hline & \multicolumn{2}{|c|}{$\begin{array}{l}\text { Remowal of Anterior } \\
\text { Pive Sezments }\end{array}$} & \multicolumn{2}{|c|}{$\begin{array}{c}\text { Nonremoval of Anterior } \\
\text { Five Sepments }\end{array}$} \\
\hline & Light & Nio hist & Light & No Light \\
\hline $\begin{array}{l}\text { Alley } \\
\text { No Alley }\end{array}$ & $\begin{array}{r}643 \\
42\end{array}$ & $\begin{array}{r}900 \\
93\end{array}$ & $\begin{array}{r}664 \\
54\end{array}$ & $\begin{array}{l}900 \\
160\end{array}$ \\
\hline
\end{tabular}


conditions were compared $(\mathrm{U}=134$, $\mathrm{p}<.05) ;(4)$ to assess the effects of the alley under the light condition for removal groups, the response times of Ss in the alley-light-removal and no-alley-light-removal conditions were compared $(\mathrm{U}=0, \quad \mathrm{p}<.005)$; and (5) to assess the effects of the alley under the light condition for nonremoval groups, the response times of Ss in the alley-light-nonremoval and no-alley-light-nonremoval conditions were compared $(U=0, p<.005)$.

Discussion

The results of this experiment confirm those of Doolittle (1971) that both the presence of light $(p<.05)$ and the absence of an alley $(p<.001)$ caused Ss to escape more quickly. As in Doolittle (1971), the alley effect had a lower significance probability than the light effect. These findings suggest that this task constitutes a fairly reliable means of assessing the effects of various variables on phototaxic and thigmotaxic responses in the earthworm.

The comparison between, removal and nonremoval groups showed that they did not differ significantly $(p>.05)$ on this task. Also, the alley-light vs no-alley-light comparisons were significant for both removal $(\mathrm{p}<.005)$ and nonremoval $(p<.005)$ groups. These findings indicate that positive thigmotaxis reduces negative phototaxis in earthworms whether or not the anterior five segments are present. Clearly, this experiment does not confirm the findings of Smith's (1902) study, in which earthworms with anterior ganglia removed were placed on a flat sheet of moist filter paper in sunlight and guided in the direction of a stack of glass slides which formed a wall with the substrate. These earthworms made contact with the wall, remained there for a short period of time, but then moved quickly away. In the alley of this experiment, Ss usually maintained partial contact with both walls of the alley, i.e., the anterior half would be touching one wall, the posterior half the other. Perhaps the difference between having one wall present and having a two-wall alley present could account for the differences in results. Several other differences, such as differences in species studied, exist. In any case, the results of the present experiment strongly indicate that the influence of thigmotaxis on phototaxis does not involve the anterior ganglia. It may be that the segmental ganglia of earthworms are more autonomous than was previously suspected.

Janzen (1931) has indicated that earthworms with their anterior ganglia removed orient poorly, and has suggested that their negative response to light is poorly directed. Experiment 1 suggested that removal earthworms escape strong light as well as nonremoval Ss. Experiment 2 compared removal and nonremoval earthworms on the accuracy of escape from a strong directional light.

\section{EXPERIMENT 2}

Forty earthworms were assigned randomly to groups calling for either the removal or nonremoval of the anterior five segments. As in Experiment 1, surgery followed Ratner \& Stein (1965). Following the 8-h recovery period, each $S$ was given one trial in the apparatus. The apparatus was the same as in Experiment 1, with three exceptions: (1) the alley was removed and not used, (2) a diameter was drawn through the 11-in. circle, (3) the bulb of the lamp was placed just above the intersection of one end of the diameter and the 11-in. circle and faced in the direction of the opposite intersection of diameter and 11-in. circle. To initiate the trial, the $S$ was placed within the 3 -in. circle with the lamp turned on. The latency and accuracy of the escape response was measured. Latency (escape response time) was measured as in Experiment 1. It was reasoned that perfect accuracy of escape response by a $S$ would consist of crossing the 11 -in. circle where it intersected with the diameter opposite the lamp. The distance between this point and the point at which the $S$ crossed the 11-in. circle, in radians, was taken as an accuracy score. The more accurate the escape response, the lower the score in radians. Record was also kept of whether the $S$ escaped using forward or backward movements. Results and Discussion

The mean response time was $139.10 \mathrm{sec}$ for the removal group and $150.05 \mathrm{sec}$ for the nonremoval group. This difference in mean response time was not significant $(t=0.33, p>.05)$. The mean escape accuracy score was 0.91 radians for the removal group and 0.65 radians for the nonremoval group-a difference which was not significant $(t=1.23, p>.05)$. Of the removal Ss, 17 of 20 escaped using backward movements, while none of the nonremoval Ss escaped using backward movements.

The results of this experiment do not support the conclusion of Janzen (1931) that earthworms orient poorly without their anterior ganglia. Although one must interpret nonsignificant results with great caution, the relatively large number of Ss run in the present experiment lends confidence to the interpretation that the role of the anterior ganglia in negative phototaxis to intense light is, at most, slight.

\section{REFERENCES}

BULLOCK. T. H.. \& HORRIDGE, G. A Structure and function in the nervous systems of incertebrates. San Francisco: Freeman, 1965.

DOOLITTLE, J. H. The effect of thigmotaxis on negative phototaxis in the earthworm. Psychonomic Science, 1971, 22. 311-312.

JANZEN, R. Beitrage zur Nervenphysiologie der Oligochaeten Zoologische Jahrbucher Abt Fuer Allegemeine Zoologie und Physiologie der Tiere. 1931.50.51-150. RATNER. S. C. \& GARDNER, L. E. Variables affecting responses of earthworms to light. Journal of Comparative \& Physiological Psychology, $1968,66,239-243$.

RATNER, S. C., \& STEIN, D. B. Responses of worms to light as a function of intertrial interval and ganglion removal Journal of Comparative \& Physiological Psy chology, 1965,59, 301-305.

SMITH, A. C. The influence of temperature. odors, light and contact on movements of the earthworm. American Journal of Physiology, 1902, 6. 459-486. 